\title{
STUDY OF PREDICTIVE ABILITY OF MODIFIED APACHE II SCORE TO PROGNOSTICATE THE OUTCOME AND SEVERITY OF GENERALIZED PERITONITIS SECONDARY TO TYPHOID ILEAL PERFORATION
}

\author{
Bhagchand Khorwal', Kuldeep Singh Yadav², Vikesh Joshi ${ }^{3}$, Irfan $^{4}$, Mukesh Sharma ${ }^{5}$, Manju Bhaskar 6 \\ ${ }^{1}$ Medical Officer, Department of General Surgery, CHC, Chomu. \\ 2Junior Resident, Department of Psychiatry, Mahatma Gandhi Medical College, Jaipur. \\ ${ }^{3}$ Senior Resident, Department of General Surgery, Government Medical College, Kota. \\ ${ }^{4}$ Senior Resident, Department of General Surgery, SMS Hospital. \\ ${ }^{5}$ Ex. Professor, Department of General Surgery, SMS Hospital, Jaipur. \\ ${ }^{6}$ Assistant Professor, Department of Psychiatry, Mahatma Gandhi Medical College, Jaipur.
}

ABSTRACT: Peritonitis (Peritoneal inflammation) may be primary, secondary or tertiary. Typhoid ileal perforation lead to secondary peritonitis that is a life threatening condition. Assessing the severity of peritonitis is important step in determining the proper treatment plan.

AIM: This study is aimed to assess the ability of modified APACHE II (Acute Physiology and Chronic Health Evaluation II) score to correctly assess the severity of generalized peritonitis secondary to ileal perforation.

MATERIALS AND METHODS: 100 patients of peritonitis secondary to ileal perforation were chosen in a one year period and were applied modified APACHE II score to assess the severity and outcome.

RESULTS: Most of perforation occurred in 2nd and 3rd decade (65\%). APACHE II score ranged from 1 to 21. Most of patients had $<9$ score. Higher APACHE II score was associated with increased mortality. Morbidity was also accurately predicted by APACHE II score.

CONCLUSION: Typhoid ileal perforation is still a common health problem causing high mortality (11\%). Compared to mortality, morbidity was less accurately predicted by APACHE II score, and more number of the patients developed more complication in higher APACHE II score group.

KEYWORDS: Peritonitis, Ileal Perforation, Apache II Score, Mortality, Morbidity

HOW TO CITE THIS ARTICLE: Bhagchand Khorwal, Kuldeep Singh Yadav, Vikesh Joshi, Irfan, Mukesh Sharma, Manju Bhaskar. "Study of Predictive Ability of Modified Apache II Score to Prognosticate the Outcome and Severity of Generalized Peritonitis Secondary to Typhoid Ileal Perforation". Journal of Evolution of Medical and Dental Sciences 2015; Vol. 4, Issue 90, November 09; Page: 15498-15501, DOI: 10.14260/jemds/2015/2217.

INTRODUCTION: Peritonitis is peritoneal inflammation due to reaction of peritoneal cavity to the contents of the perforated viscera. Perforation occurs when the wall of a hollow viscus develops a hole through its entire thickness.

It can be categorized into three stages based upon the nature \& source of microbial contamination. Primary peritonitis is an infection without any visceral perforation, usually from extra-peritoneal source and monomicrobial in origin. Secondary peritonitis is the most common \& follows an intra-peritoneal source usually from perforation of hollow viscera (Infectious like typhoid or non-infectious causes like duodenal ulcer perforation, blunt trauma of abdomen etc.). On treatment failure it usually develops into tertiary stage that is potential fatal affliction although advances are available in diagnosis, surgical techniques, antimicrobial therapy \& intensive care support.[1]

Acute generalized peritonitis from typhoid ileal perforation is a potentially life-threatening condition. It is a common surgical emergency in many general surgical units

Financial or Other, Competing Interest: None.

Submission20-10-2015, Peer Review 21-10-2015,

Acceptance 29-10-2015, Published 06-11-2015.

Corresponding Author:

Dr. Bhagchand Khorwal,

D. No. C-46, Sahyog Apartment, Tower 2,

Sector 6, Vidhyadhar Nagar, Jaipur.

E-mail:drbhagi84@gmail.com

DOI: $10.14260 /$ jemds/2015/2217. in the developing countries and is often associated with high morbidity and mortality.[2,3]

Grading the severity of acute peritonitis assists in decision making and has made therapy ameliorated for the management of severely ill patients.[4] The assessment of risk considering various clinical parameters to evaluate new therapies, monitor resource utilization, quality of care improvement is of immense value at present.[5,6]

Many scoring systems are available that helps to measure \& stratify the condition of critically ill patients and thus helps the clinicians in better resource allocation as per the needs of the patient and feasibility of outcome expected.[7] Amongst them APACHE II (Acute Physiological and Chronic ill Health Evaluation), is widely used.

The aim of study is to assess the use of modified APACHE II score in predicting the outcome and in assessing the severity of generalized peritonitis secondary to typhoid ileal perforation.

MATERIALS \& METHODS: This was a prospective study conducted at SMS Medical College \& attached group of Hospital, Jaipur in Department of general surgery from October 2011 to October 2012 to assess the use of modified APACHE II score \{In 1981, Knauss et al. developed the Acute Physiology And Chronic Health Evaluation Score (APACHE) based on 34 physiological parameters. APACHE II was later developed as a simplified clinically useful system using 12 physiological variables.[8,9]\} to assess the severity and predicting, the outcome of generalized peritonitis secondary to typhoid ileal perforation. 
A Performa was devised to note patient's particular history physical finding \& investigation of patient. Assuming $80 \%$ complication rate sample size was calculate at $80 \%$ power $\alpha$ error. 05 , sample size of 100 patients was obtained at sampling error of $10 \%$.

All patients of generalized peritonitis were evaluated with APACHE II score and underwent emergency laparotomy. Patients other than typhoid ileal perforation are excluded from the study. The surgical procedure employed to repair perforation either simple primary closure or resection anastomosis with or without proximal ileostomy. APACHE II was calculated according to Knauss et al., mortality was defined as any death during the hospital stay.

The statistical software namely SPSS 20.0 was used for the analysis of the data and Microsoft word was used to generate graphs, tables etc.

RESULTS: Most of perforation occurred in 2nd and 3rd decade (65\%). Only 3 cases were over 60 years among 100 cases. In this study there were 83(83\%) males and 17(17\%) females. Male to female ratio was 5:1.

Mortality in our study was $11 \%$ (Table no 1). 59\% patients in our study developed complications which include wound infections in 54\%, wound dehiscence in $19 \%$, intraabdominal collection in $17 \%$ and leak in $3 \%$ (Table no 2).

APACHE II score ranged from 1 to 21. Most of patients had $<9$ score (Table no 3). Correlation between age and mortality was not significant statistically. (Table no 4).

Higher APACHE II score was associated with increased mortality (Table no 5). Morbidity was also accurately predicted by APACHE II score. Still higher APACHE II score was associated with increased mortality. (Table no 6).

DISCUSSION: Perforation peritonitis is a common cause of surgical emergency. The severity assessment of a disease condition is useful for early priorities treatment, and it reduce mortality and morbidity. High severity score associated with high mortality and morbidity, there for these Patients may require more intensive treatment then with low severity score.

Enteric Perforation and Sex: In our study out of 100 subjects 83 were male. Male to female ratio was 4.9:1. In another study done in a University teaching hospital in Northwestern Tanzania by Phillipo L Chalya et. al [10] showed that male are twice more commonly affected by enteric perforation than female. Bailiga, 1949 [11] found male to female ratio of 3.8:1. N.D. Swadia \& P.M. Trivedi, 1979 [12] found $84 \%$ incidence in male. All results were well supported by our study and showed a male preponderance for enteric perforation.

Enteric Perforation and Age: In our study mean age was $30.19 \mathrm{y} \mathrm{r}$ with the range of $13-70$ years. $65 \%$ patients were in 11-30 year age group while $82 \%$ were below 40 year age. Salih Hosoglu et. al. 2004.[13] found mean age of 28.2 years; range 16-74 years in cases of enteric perforation.

In another study by Phillipo L Chalya et. al.[10] showed that ages ranged from 8 to 76 years with a median age of 18.5 years in enteric perforation.
The peak age incidence was in the 11-20 years age group. In our study peak age group was 21-30 (41.6\%).22.5\% was in 11 -20 year age group.

M. laiq-uz-zaman, S. N. Alam et al [14] from Karachi found that $60 \%$ patients were belonged to $25-40$ year age group while range was $12-60$ year. These all results are very similar to our result and shows that most of the patients were of younger age group mostly below 40 year in the range of 20-40 years.

Outcome of enteric perforation \& age: Out of 100 patients 89 survived. Mean age among survivors was 30.28 while among non-survivors, it was 29.40. Statically it was insignificant 5 (45.5\%) out of 11 death occur in 21-30 year age group. $27.3 \%$ patients in the 11-20 year age group (3 out of 23) died. 1 death occur in 31-40 year age group(9.1\%).

These results (death) were according to number of total patients in that particular age group. Statistically age had no effect on outcome as p value was 0.722 .

M. laiq-uz-zaman. ${ }^{[14]}$ showed that age had no effect on prognosis ( $p$ value was 0.232). Salih Hosoglu et. al. 2004.[13] found age as a significant variable for risk of perforation: age ( $>40$ years) (OR $=4.67,95$ percent $\mathrm{CI}: 1.27,17.10 ; \mathrm{p}=0.01)$, they didn't show any effect on outcome. All these results were comparable with our study and showing age as an insignificant variable to predict outcome in enteric perforation.

Morbidity \& mortality in enteric perforation: In our present study overall mortality \& morbidity was $11 \%$ and 59\% respectively. Operative mortality was $0 \%$. Dickson and Cole (1964).[15] reported 38 cases of ileum perforation in which 22 patients died at operation. 17 patients had complication of wound infection, 10 pelvic abscess and burst abdomen.

Vyas (1964).[16] reported $42 \%$ morbidity which includes basal pneumonia in 4 cases, wound infection in 7 , burst, abdomen in one, fecal fistula in one, reperforation in 2 , renal failure and jaundice one, Bhansali (1967).[17] reported morbidity to be maximum in enteric perforation was superadded by debilitated illness, respiratory complication etc. Mortality in this group was 48\%. Sepaha and Chhabra (1970).[18] studied 60 patients of enteric Perforation in which mortality was $25.3 \%$. Patient treated within 24 hour had low mortality. Our study shows a better outcome in cases of enteric perforation peritonitis. This might he due to availability of newer higher generation antibiotics, better perioperative care, and availability of intensive care facilities as all above mention studies were done approximately 3-4 decade earlier.

Abdul Ghaffar Ansari et al (2009).[19] showed 13.36\% death rates in cases of enteric perforation peritonitis with morbidity of $68.3 \%$, Muhamad S. Abdullah.[20] recorded $8 \%$ mortality in non-traumatic perforation of small bowel in which typhoid was the most common cause. Abdul Rashid K. et al 2005.[21] found mortality of $17.5 \%$ in a series of 80 patients who underwent surgical management (laparotomy) for enteric perforation peritonitis. Our study very well sported by those results, showing mortality of $11 \%$ with $59 \%$ morbidity.

The APACHE II score and outcome: The modified APACHE II score range from 1-21. The mean APACHE II score was 6.71. The mean APACHE II score for survivor 6.06 and 12 in those who died. 


\section{We stratified the study group into four categories according to APACHE II score:}

1. The first group who scored $0-4: 33 \%$ patient came in this group, 33 patient out of 100.There was no mortality (0\%), 42.4\% had wound infection. 9.1\% had wound dehiscence, $3 \%$ had intra-abdominal collection and leak rate was $0 \%$.

2. The second group who scored 5-9: $46 \%$ patient came in this group, 46 patients out of 100.There was $8.7 \%$ mortality (4 patients). 58.7\% had wound infection, $15.2 \%$ had wound dehiscence, $21.7 \%$ had intraabdominal collection and leak rate was $4.3 \%$.

3. The third group who scored $10-14: 16 \%$ patient came in this group, 16 patients out of 100 .There was $25 \%$ mortality (4 patients). $62.5 \%$ had wound infection, $50 \%$ had wound dehiscence, $25 \%$ had intra-abdominal collection and leak rate was $6.2 \%$.

4. The fourth group who scored $>/=15: 5 \%$ patient came in this group, 5 patient out of 100 . There was $60 \%$ mortality (3 patients). 60\% had wound infection, 19\% had wound dehiscence, $17 \%$ had intra-abdominal collection and leak rate was $3 \%$.

MR Capoor, (2008).[22] found higher the APACHE II score $(>13)$ higher the mortality in enteric perforation. In that study APACHE II score $>13$ was associated with mortality of $46.2 \%$ and $100 \%$ morbidity as all 13 patients had wound infection. APACHE II score $<10$ was associated with $0 \%$ mortality and $20 \%$ morbidity in that study.

Adesunkanmi ARK et al.[23] work on acute generalized peritonitis in 69 children patients. APACHE II score ranged from 0 to 18, mean 8.5 SD 5. For survivors, the mean score was 8; for non-survivors, 13. Eight patients died (11.6\%); four of $63(6.4 \%)$ patients who scored 0-15 died; four of six (66.7\%) patients who scored 16-18 ( $p<00.05)$ died. A modified APACHE II score greater than 15 was associated with a significantly greater mortality in that study.

Abdul Rashid K. Adesunkanmi, (2005).[21] found that modified APACHE II score ranged from 0-19, with a mean of $8.2+4,7.6+4$ for survivors an $9.4+2$ in those who died, in cases of enteric perforation peritonitis. There was no death among the Patients who scored 0-4, whereas mortality was $13 \%$ in those who scored $5-9,41.2 \%$ in those who scored $10-14$, and $50 \%$ in patients who scored $15-19(\mathrm{p}<0.05)$.

All of these studies were well supported by our study and showing that higher the APACHE II score higher the mortality was. Although morbidity was less accurately predicted by APACHE II score more no of the patients developed complications in higher APACHE II score group.

CONCLUSION: Typhoid ileal perforation is still a common health problem causing high mortality of $11 \%$. Males are more commonly affected while second and third decades are the most common age of presentation. Higher the APACHE II score higher was the mortality. Compared to mortality, morbidity was less accurately predicted by APACHE II score, still more no of the patients developed more complication in higher APACHE II score group.

\section{REFERENCES:}

1. Sahu SK, Gupta A, Sachan PK and Bahl DV. Outcome of secondary peritonitis based on Apache II Score. The Internet Journal of Surgery. 2008; 14:2.

2. Adesunkanmi ARK, Ajao OG. The prognostic factors in Typhoid Ileal perforation. A prospective study of 50 patients. J Roy Coll. Surg Edinb 1997; 42:395-9.

3. Adesunknami ARK, Badmus TA, Ogundoyin O. Causes and determinant of outcome of intestinal obstruction in a semi urban African Community. Ann Coll Surg HK 2003; 7:116-23.

4. Ponling GA, Sim AJW, Dudley HAF. Comparison of local and systemic of sepsis in predicting survival. Br J Surg. 1987; 74:750-2.

5. Kanus WA, Dropper EA, Wagner DR, Zimmerman JE. APACHE severity of disease classification system. Crit Care Med. 1985; 13: 818-29

6. Civelta JM, Hudson-Civeua JA, Nelson LD. Evaluation of APACHE II for cost containment and quality assurance. Ann Surg. 1990; 212:266-76.

7. Baker SP, O'Neil 'B, Haddon WQ Long WB. The injury severity score. A method for describing pattern of patients with multiple injuries and evaluating emergency cases. J Trauma. 1974; 14:187.

8. Knaus WA, Zimmerman JE, Wagner DP, Draper EA, Lawrence DE. APACHE - acute physiology and chronic health evaluation: a physiological based classification system. Crit Care Med. 1981; 9:591-7.

9. Knaus WA, Draper EA, Wagner DP, Zimmerman JE. APACHE II-acute physiology and chronic health evaluation: a severity of disease classification system. Crit Care Med. 1985; 13:818-29.

10. Chalya, P. L., Mabula, J. B., Koy, M., Kataraihya, J. B., Jaka, H., Mshana, S. E., Gilyoma, J. M. (2012). Typhoid intestinal perforations at a University teaching hospital in Northwestern Tanzania: A surgical experience of 104 cases in a resource-limited setting. World Journal of Emergency Surgery: WJES, 7, 4.

11. Bailiga AV: Surgical complications of Typhoid; Indian J Surg 1949; 11:166-77.

12. Swadia ND, Trivedi PM, Thakkar AM. Problem of enteric ileal perforation. Indian J Surg 1979; 41:643-651.

13. Salih Hosoglu, Mustafa Aldemir, Serife Akalin, Mehmet Faruk Geyik, Ibrahim H. Tacyildiz, and Mark Loeb. Risk Factors for Enteric Perforation in Patients with Typhoid Fever. Am J Epidemiol 2004; 160:46-50.

14. Muhammad laiq uz zaman khan, Shams Nadeem alam, jahanzaib haider, Khalid ahsan malik.Prognostic factors in typhoid enteric perforation.pakistan journal of psychiatry 2009;25:101-5.

15. Dickson, J. A. S. and Cole, G. J. (1964), Perforation of the terminal ileum. A review of 38 cases. Br J Surg, 51: 893-897.

16. Vyas PN. Study of 15 cases of intestinal perforation in enteric fever. Indian J Surg 1964; 26:1-8.

17. Bhansali, S.K. (1967) .Gastrointestinal perforation: A clinical study of 96 cases. Journal of Postgraduate Medicine, 13, 1.

18. Sepaha GC, Khandekar JD, Chabra ML. Enteric perforation. A study of 60 cases. J Indian Med Assoc. 1970 Jun 16; 54(12):558-61. 
19. Abdul Ghaffar Ansari, Syed Qaiser Hussain Naqvi, Ali Akbar Ghumro, Abdul Hakeem Jamali, Altaf Ahmad Talpur. Management of typhoid ileal perforation:a surgical experience of 44 cases. Gomal Journal of Medical Sciences January-June 2009, Vol. 7: 27-30.

20. Muhamad S. Abdullah, Raid E. Rassam,Tawfiq J. Almarzooq. A study of 82 patients of non-traumatic terminal ileal perforation in Al-Kindy teaching hospital. Fac Med Baghdad 2011; Vol. 53:147-151.

21. Adesunkanmi ARK, Badmus TA, Fadiora FO, Agbakwuru EA. Generalized peritonitis secondary to typhoid ileal perforation: Assessment of severity using modified APACHE II score. Indian J Surg 2005; 67:2933.

\begin{tabular}{|c|c|c|}
\hline Death & Frequency & Percent \% \\
\hline no & 89 & 89.0 \\
\hline Yes & 11 & 11.0 \\
\hline Total & $\mathbf{1 0 0}$ & $\mathbf{1 0 0 . 0}$ \\
\hline \multicolumn{2}{|c|}{ Table 1: Distribution of survivors } \\
and non-survivors patients \\
\hline
\end{tabular}

\begin{tabular}{|c|c|c|}
\hline Morbidity & Frequency & Percent \\
\hline No & 41 & 41.0 \\
\hline Yes & 59 & 59.0 \\
\hline Total & $\mathbf{1 0 0}$ & $\mathbf{1 0 0 . 0}$ \\
\hline Table 2: Frequency distribution of morbidity: \\
\hline
\end{tabular}

\begin{tabular}{|c|c|c|}
\hline APACHE Cat. & No. of patients & Percent \\
\hline $0-4$ & 33 & 33 \\
\hline $5-9$ & 46 & 46 \\
\hline $10-14$ & 16 & 16 \\
\hline$>/=15$ & 5 & 5 \\
\hline Total & $\mathbf{1 0 0}$ & $\mathbf{1 0 0}$ \\
\hline \multicolumn{2}{|c|}{$\begin{array}{c}\text { Table 3: Frequency of APACHE II } \\
\text { scores for all patients }\end{array}$} \\
\hline
\end{tabular}

22. Capoor M R, Nair D, Chintamani M S, Khanna J, Aggarwal P, Bhatnagar D. Role of enteric fever in ileal perforations: An overstated problem in tropics?. Indian J Med Microbiol 2008;26:54-7.

23. A. R. K. Adesunkanmi, S. A. Oseni, O. Adejuyigbe andE. A. Agbakwuru. Acute generalized peritonitis in African children: assessment of severity of illness using modified APACHE II score. ANZ Journal of Surgery 2003 ;73: 275279.

\begin{tabular}{|c|c|c|c|c|}
\hline \multirow{2}{*}{ Age group } & \multicolumn{2}{|c|}{ Death } & \multirow{2}{*}{ Total } & \multirow{2}{*}{ percent } \\
\cline { 2 - 5 } & No & yes & & 13 \\
\hline 11-20 years & 20 & 3 & 23 & 11.9 \\
\hline 21-30 years & 37 & 5 & 42 & 5.9 \\
\hline 31-40 years & 16 & 1 & 17 & 11.9 \\
\hline $41-50$ years & 8 & 1 & 9 & 0 \\
\hline 51-60 years & 6 & 0 & 6 & 33.3 \\
\hline >60 years & 2 & 1 & 3 & Table 4: Relation between Age and Mortality: \\
\hline
\end{tabular}

\begin{tabular}{|c|c|c|c|}
\hline \multirow{2}{*}{ APACHE Cat. } & \multicolumn{2}{|c|}{ Death } & \multirow{2}{*}{ Mortality \% } \\
\cline { 2 - 3 } & No & yes & 0 \\
\hline $0-4$ & 33 & 0 & 8.7 \\
\hline $5-9$ & 42 & 4 & 25 \\
\hline $10-14$ & 12 & 4 & 60 \\
\hline$>/=15$ & 2 & 3 & Table 5: Association between \\
\hline \multicolumn{4}{|c|}{ APACHE II Score and Mortality } \\
\hline
\end{tabular}

\begin{tabular}{|c|c|c|c|c|}
\hline \multirow{2}{*}{ APACHE Cat. } & \multicolumn{2}{|c|}{ Complication } & \multirow{2}{*}{ Total } & \multirow{2}{*}{$\%$} \\
\cline { 2 - 5 } & No & Yes & & 42.4 \\
\hline $0-4$ & 19 & 14 & 33 & 60.9 \\
\hline $5-9$ & 18 & 28 & 46 & 75.0 \\
\hline $10-14$ & 4 & 12 & 16 & 100.0 \\
\hline$>/=15$ & 0 & 5 & 5 & \\
\hline Total & 41 & 59 & 100 & \\
\hline \multicolumn{5}{|c|}{ Table 6: Association between } \\
APACHE II score and morbidity \\
\hline
\end{tabular}

